Check for updates

Cite this: Chem. Commun., 2017, 53,9842

Received 21st June 2017,

Accepted 4th August 2017

DOI: $10.1039 / c 7 c c 04823 h$

rsc.li/chemcomm

\section{2,2-Diiododimedone: a mild electrophilic iodinating agent for the selective synthesis of $\alpha$-iodoketones from allylic alcohols $\dagger$}

\author{
Samuel Martinez-Erro, $\$$ Antonio Bermejo Gómez, (D) $\ddagger$ Ana Vázquez-Romero, \\ Elis Erbing and Belén Martín-Matute (D) *
}

\begin{abstract}
2,2-Diiodo-5,5-dimethylcyclohexane-1,3-dione is reported as a new electrophilic iodinating agent that selectively iodinates electron-rich aromatics. In contrast to other common electrophilic iodinating reagents, its mild nature allows it to be used for the selective synthesis of $\alpha$-iodinated carbonyl compounds from allylic alcohols through a 1,3-hydrogen shift/iodination process catalyzed by iridium(III) complexes.
\end{abstract}

Halogenated organic compounds are ubiquitous, not only as natural products, ${ }^{1}$ but also as synthetic compounds, and they have applications in medicinal chemistry, ${ }^{2}$ agrochemistry, ${ }^{3}$ and materials science. ${ }^{4}$ The halogen functional group is very versatile. It can participate in many synthetic transformations, including nucleophilic substitutions, eliminations, dehydrohalogenations, and oxidative additions to metal centers. The nature of the halogen gives each carbon-halogen bond unique properties, ${ }^{5}$ resulting in numerous applications in synthetic organic chemistry.

Significant progress has been made in the development of synthetic methods for the construction of C-F bonds, via both electrophilic and nucleophilic approaches. ${ }^{6}$ There also exist many synthetic methods for the nucleophilic and electrophilic chlorination $^{7}$ and bromination ${ }^{8}$ of organic molecules. When it comes to electrophilic methods for the construction of C-I bonds, reagents such as $\mathrm{I}_{2}$, NIS ( $N$-iodosuccinimide), $\mathrm{IPy}_{2} \mathrm{BF}_{4}$ (Barluenga's reagent), and ICl have been widely used in organic synthesis. ${ }^{9}$ Also, methods based on the conversion of iodide into the corresponding iodonium species through oxidation have also been reported.$^{10}$ These methods have some drawbacks, however, such as the high reactivity of the electrophilic iodinating agents, or the need for strong oxidizing agents, which result in low functional-group tolerance and low chemo- or regioselectivity. Thus, the development of mild and selective electrophilic

Department of Organic Chemistry, Arrhenius Laboratory, Stockholm University, 10691 Stockholm, Sweden. E-mail: belen.martin.matute@su.se

$\dagger$ Electronic supplementary information (ESI) available: Detailed synthetic procedures, characterization, NMR spectra, optimization tables and deuterium labelling studies. See DOI: 10.1039/c7cc04823h

¥ These authors contribute equally to this work. iodination methods remains a challenging and desirable goal for synthetic chemists.

We have previously reported the use of iridium catalysts for the conversion of allylic alcohols (1) into $\alpha$-functionalized carbonyl compounds. ${ }^{11,7 c, 8 c, 12}$ Carbon and halogen (i.e., $\mathrm{F}, \mathrm{Cl}$, and $\mathrm{Br}$ ) functional groups could be introduced through a process involving a 1,3-hydrogen shift mediated by the metal complex. This process allows the selective formation of either the $\alpha$ or $\alpha^{\prime}$ constitutional isomer, as the new bond is constructed exclusively at the carbon that was originally part of the olefin. Attempts to introduce an iodide failed in our hands, mainly due to the high reactivity of the available electrophilic iodinating agents, but also due to the instability of the starting allylic alcohols and/or the final iodoketones under the reaction conditions. In this communication, we report the development of a new mild iodinating agent (Scheme 1, top) and its application in electrophilic iodination of aromatic compounds, and also in the synthesis of $\alpha$-iodoketones (3) from allylic alcohols mediated by iridium catalysts (Scheme 1, bottom). This methodology allows for the first time the one-step synthesis of $\alpha$-iodoketones as single constitutional isomers from allylic alcohols in a one-step procedure. The utility of $\alpha$-iodoketones for the preparation of valuable building blocks is also presented.
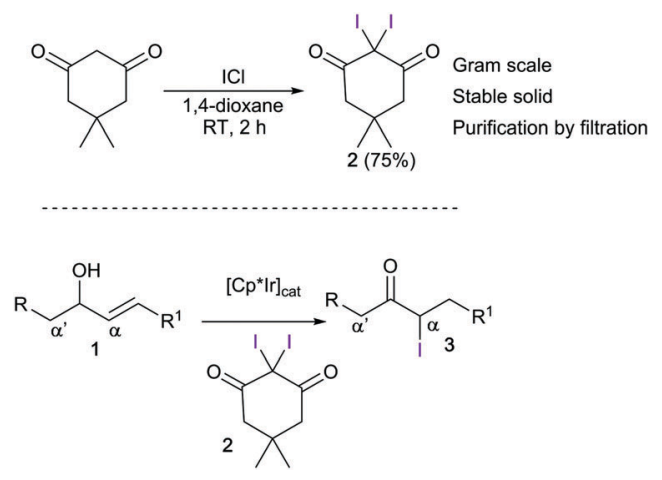

Scheme 1 Synthesis of 2,2-diiododimedone (2, top) and of $\alpha$-iodocarbonyl compounds from allylic alcohols. 
The synthesis of the new iodinating reagent, 2,2-diiododimedone (2), was easily accomplished by the treatment of dimedone with iodine monochloride in 1,4-dioxane at room temperature. The synthesis of $\mathbf{2}$ can be carried out on a gram scale, and purification by simple filtration gives the product in excellent yield. We initially tested $\mathbf{2}$ as an iodinating agent for aromatic compounds (Scheme 2). In optimization studies, the best results were obtained using a catalytic amount of $\mathrm{FeCl}_{3}$, and hexafluoroisopropanol (HFIP) as the solvent. The need to use these conditions reflects the mildness of 2, which is important for increasing the functional group tolerance in electrophilic halogenation reactions. After a short optimization (see ESI $\dagger$ ), we found that anisole 4 a could be iodinated under an air atmosphere in just $2 \mathrm{~h}$. Two other substrates were also iodinated using these reaction conditions; both $N, N$-dimethylaniline (4b) and $N$-pivaloyl indole (4c) were converted into the corresponding iodinated analogues (5b and $\mathbf{5 c}$ ) in very good yields after short reaction times and with excellent regioselectivity.

Next, we evaluated the performance of 2 in the iridiumcatalyzed isomerization/ $\alpha$-iodination of allylic alcohols. For a successful outcome, the reaction must take place under mild conditions, and the starting alcohols (1) and final products (3) should not undergo undesired iodination. Oct-1-en-3-ol (1a) was chosen as a model substrate for the optimization studies, and several $\operatorname{Ir}(\mathrm{III})$ catalysts and solvents were evaluated (Table 1). When $\left[\mathrm{Cp}^{*} \mathrm{IrCl}_{2}\right]_{2}$ (I, $2 \mathrm{~mol} \%$ [Ir]) was used as the catalyst in a mixture of acetone and $\mathrm{H}_{2} \mathrm{O}(1: 1)$, full conversion was observed, but only $34 \%$ of the desired product $3 \mathbf{a}$ was formed, together with $64 \%$ of $\alpha, \beta$-unsaturated ketone 6a (entry 1). This solvent mixture gave, on the contrary, excellent results in the bromination of allylic alcohols. ${ }^{8 c}$ The use of $\mathrm{THF} / \mathrm{H}_{2} \mathrm{O}(1: 1)$ resulted in a clear decrease in the formation of $\mathbf{6 a}$ (entry 2). This effect was even clearer when THF was replaced by 2-methyltetrahydrofuran (2-MeTHF). In this case, the desired $\alpha$-iodinated compound (3a) was obtained in $85 \%$ yield and only $11 \%$ of 6 a was formed (entry 3). The amount of $\mathbf{6 a}$ could be decreased further by using $\left[\mathrm{Cp}^{*} \operatorname{Ir}\left(\mathrm{H}_{2} \mathrm{O}\right)_{3}\right] \mathrm{SO}_{4}(\mathrm{II})$ or $\left[\left(\mathrm{Cp}^{*} \mathrm{Ir}\right)_{2}(\mathrm{OH})_{3}\right] \mathrm{OH} \cdot 11 \mathrm{H}_{2} \mathrm{O}$ (III) as the catalyst (entries 4 and 5). When the proportion of $\mathrm{H}_{2} \mathrm{O}$ in the solvent mixture was increased (i.e., 1:2), higher amounts of the undesired $\mathbf{6 a}$ were formed (entries 6 and 7); when the proportion of 2-MeTHF was increased, the yield of $\mathbf{6 a}$ dropped to just $5-6 \%$ (entries 8 and 9), while a very good yield for $3 \mathbf{a}$ was maintained. Increasing the proportion of 2-MeTHF further did not prevent the formation of $\mathbf{6 a}$, and also compromised the conversion (see the ESI $\dagger$ for a full description of solvent effects).

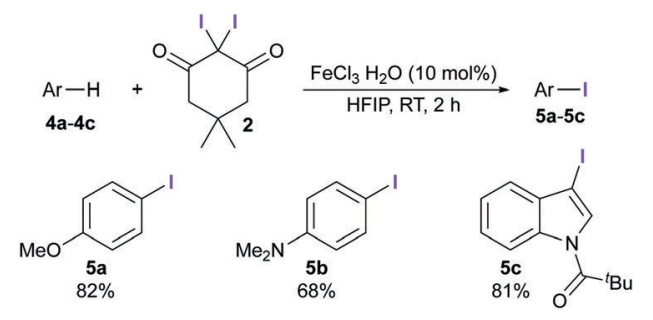

Scheme 2 lodination of electron-rich aromatics using 2.
Table 1 Optimization ${ }^{a}$

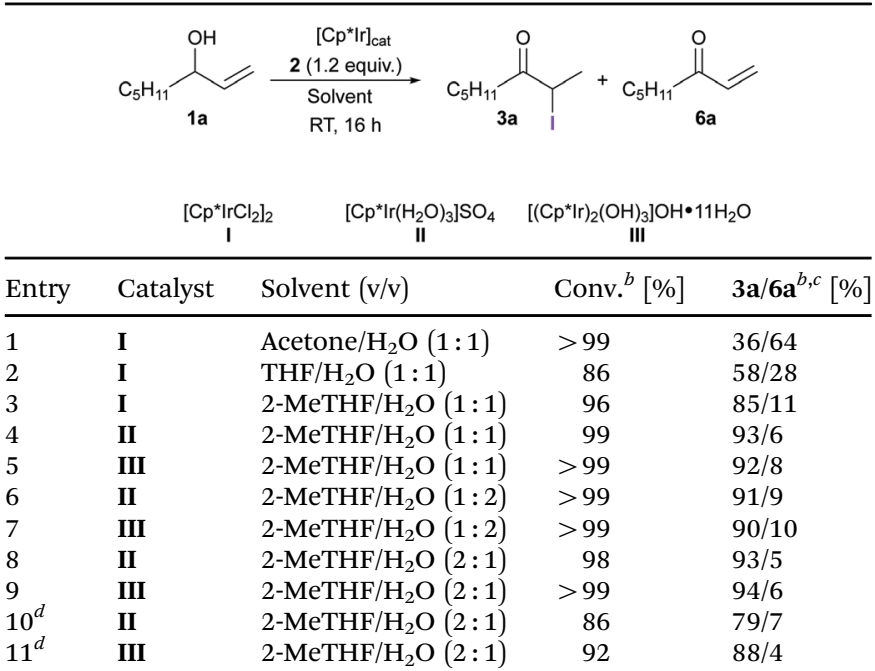

${ }^{a}$ Unless otherwise noted, 1a $(0.5 \mathrm{mmol}, 0.1 \mathrm{M})$ and $2 \mathrm{~mol} \%$ of [Ir] were used. ${ }^{b}$ Determined by ${ }^{1} \mathrm{H}$ NMR spectroscopy. ${ }^{c}$ Octan-3-one was not formed. ${ }^{d} 1 \mathrm{~mol} \%$ of [Ir].

When the catalyst loading was decreased to $1 \mathrm{~mol} \%$ [Ir], catalyst III was better than II (entries 10 and 11). When 0.6 and 0.2 equiv. of 2 were used, yields of 70 and $27 \%$, respectively, were observed (see ESI $\dagger$ ). This result suggests that more than one iodo unit can be donated by the reagent. All reactions were carried out under an atmosphere of air.

When compared to other electrophilic iodinating reagents, the superiority of 2 was clearly seen (Table 2). None of the other reagents tested were able to give good yields of $\mathbf{3 a}$, mainly due to the decomposition of the starting allylic alcohol 1a (entries 1-5). This is not surprising, since it is well known that double bonds promptly react with these reagents to give cyclic iodonium ions. This undesired reaction was not observed when 2,2-diiododimedone

Table 2 Evaluation of a variety of iodinating agents ${ }^{a}$

\begin{tabular}{|c|c|c|c|}
\hline \multirow[b]{2}{*}{ Entry } & 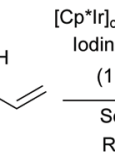 & $\begin{array}{r}{ }_{5} \mathrm{H}_{11} \\
3 \mathbf{a}\end{array}$ & \\
\hline & Reagent & Conv. $^{b}[\%]$ & $3 \mathbf{a} / \mathbf{6} \mathbf{a}^{b}[\%]$ \\
\hline 1 & 2 & $>99$ & $94 / 6$ \\
\hline 2 & $\mathrm{I}_{2}$ & 66 & $-13^{c}$ \\
\hline 3 & ICl & 66 & $-/ 1^{c}$ \\
\hline 4 & NIS & $>99$ & $17 /-$ \\
\hline 5 & $\mathrm{IPy}_{2} \mathrm{BF}_{4}$ & $>99$ & $-1-$ \\
\hline 6 & - & $<5$ & - \\
\hline 7 & $2^{d}$ & 4 & - \\
\hline 8 & $\mathrm{I}_{2}^{d}$ & 25 & $-^{e}$ \\
\hline 9 & $\mathrm{ICl}^{d}$ & 95 & $-^{e}$ \\
\hline 10 & $\mathrm{NIS}^{d}$ & 90 & $-^{e}$ \\
\hline 11 & $\mathrm{IPy}_{2} \mathrm{BF}_{4}{ }^{d}$ & 76 & $-^{e}$ \\
\hline
\end{tabular}

${ }^{a}$ Unless otherwise noted, 1a $(0.5 \mathrm{mmol}, 0.1 \mathrm{M}) \cdot{ }^{b}$ Determined by ${ }^{1} \mathrm{H}$ NMR spectroscopy. ${ }^{c} 28 \%$ (entry 2) and $21 \%$ (entry 3 ) of octan-3one were formed. ${ }^{d}$ Without [Ir] catalyst. ${ }^{e} \mathrm{~A}$ mixture of unknown byproducts was observed. 
(2) was used. A series of control experiments was also carried out (Table 2, entries 6-11). Catalyst III alone was not able to react with the allylic alcohol in the absence of 2 (entry 6 ). We recently reported that the presence of a halogen ligand on Ir is important for the activity of [Cp* $\mathrm{Cr}]$ complexes of this type, and described the in situ formation of such an Ir-halogen bond through the reaction of the Ir precatalyst with the halogenating agent. ${ }^{13}$ In another control experiment, we observed that 2 does not react with allylic alcohol 1a in the absence of the iridium catalyst after $16 \mathrm{~h}$ (entry 7). It can therefore be concluded that the mildness of the iodinating agent $\mathbf{2}$ is key to the success of this tandem isomerization/halogenation reaction. Mechanistic investigations were carried out with deuterium-labelled alcohols, and the results suggest that an intramolecular 1,3-H shift is operating under these reaction conditions (see ESI $\dagger$ ).

Having established these optimized reaction conditions, we went on to study the scope of the reaction (Table 3). Alcohols 1a-1f and 1k-1m bearing a terminal double bond gave the corresponding $\alpha$-iodocarbonyl compounds (3a-3f and $\mathbf{3 k} \mathbf{k}-\mathbf{3 m}$ ) in high yields within $16 \mathrm{~h}$. Allylic alcohols with internal double bonds $(\mathbf{1} \mathbf{g}-\mathbf{1 j})$ were also converted into the corresponding $\alpha$-iodinated products in good yields. Additional double bonds in the molecule were unaffected (1f and 19); only the allylic alcohol functionality reacted. The reaction is not restricted to

Table 3 Substrate scope

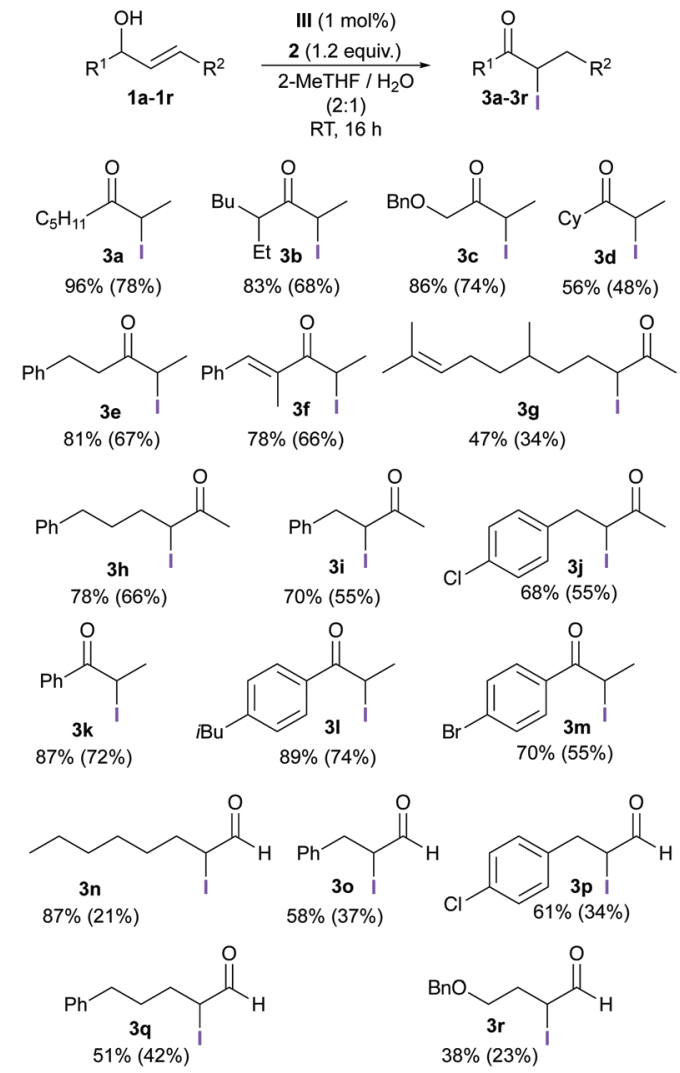

${ }^{a}$ Reactions carried out on a $1 \mathrm{mmol}$ scale $(0.1 \mathrm{M})$. Yield determined by ${ }^{1} \mathrm{H}$ NMR spectroscopy. Isolated yields in parentheses.

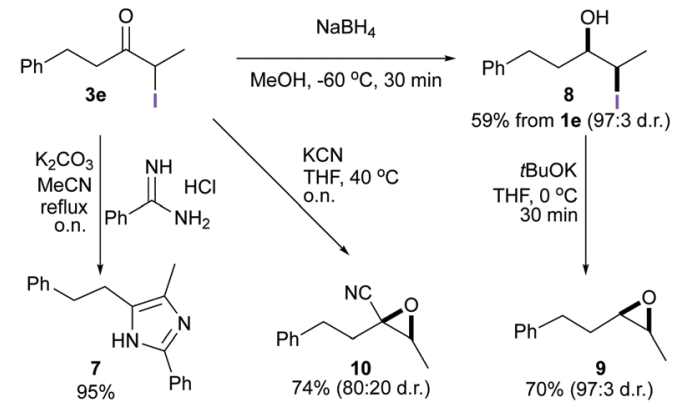

Scheme $3 \alpha$-lodoketones as versatile synthetic intermediates.

secondary alcohols; primary alcohols gave the corresponding $\alpha$-iodoaldehydes (3n-3r) in moderate to good yields. The stability of the products during the purification process accounts for the difference between the yields estimated against an internal standard and the isolated yields.

The utility of $\alpha$-iodoketones as versatile intermediates for organic synthesis was demonstrated in a series of transformations (Schemes 3 and 4). First, the synthesis of imidazole 7 was easily accomplished by allowing an amidine to react with $\alpha$-iodoketone 3e. In a one-pot procedure starting from 1e, iodohydrin 8 was synthesized in $59 \%$ yield with excellent diastereoselectivity $(93: 7)$. Subsequent basic treatment gave the corresponding epoxide 9 with excellent diastereoselectivity. $\alpha$-Cyanoepoxide 10 was also prepared in good yield and with a good diastereomeric ratio in one step by the reaction of $\mathbf{3 e}$ with KCN.

The synthetic utility of $\alpha$-iodocarbonyl compounds was also demonstrated via the preparation of valuable $\alpha$-aminoketones. This structural motif is found in many compounds with important biological activities. ${ }^{14}$ Although there are several procedures for the synthesis of compounds containing this motif, their regioselective preparation when two enolizable positions are present remains a challenge. ${ }^{14 b-d}$ We found that secondary amines react with $\alpha$-iodocarbonyl derivatives - prepared from allylic alcohols as described in this communication - to give $\alpha$-amino ketones as single constitutional isomers (Scheme 4).

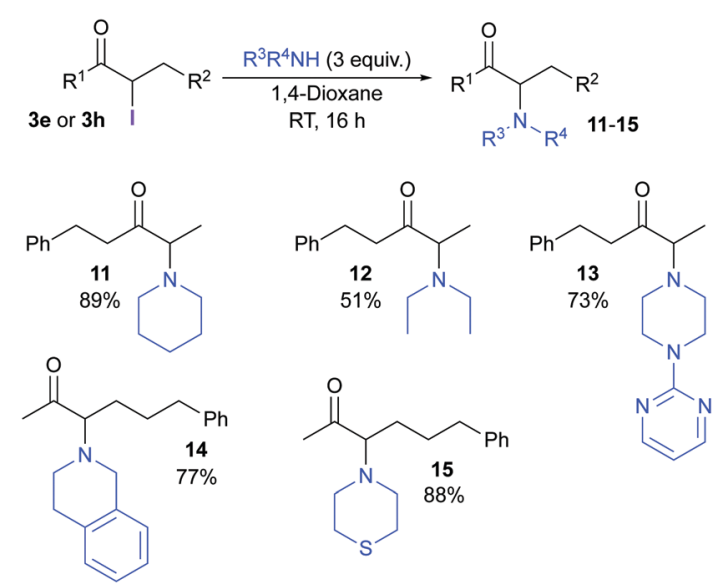

Scheme 4 Regioselective synthesis of $\alpha$-amino ketones. 
In conclusion, we present a new mild and selective electrophilic iodinating reagent, 2,2-diiododimedone (2). Using this reagent, we have been able to carry out the first selective synthesis of $\alpha$-iodocarbonyl compounds as single constitutional isomers. The method relies on an iridium-catalyzed 1,3-hydrogen shift mediated by iridium(III) complexes. The utility of $\alpha$-iodocarbonyl compounds has been demonstrated by their conversion into other important organic structures for which selective synthetic procedures have not previously been available.

This project was supported by the Swedish Research Council (VR), the Swedish Research Council Formas, and the Knut and Alice Wallenberg Foundation. We also thank the Swedish Governmental Agency for Innovation Systems (VINNOVA) for a VINNMER grant to B. M.-M.

\section{Conflicts of interest}

There are no conflicts to declare.

\section{Notes and references}

1 (a) M. M. Haeggblom and I. D. Bossert, Dehalogenation, Kluwer Academic Publishers, New York, 2003, pp. 6-29; (b) G. W. Gribble, Naturally occurring organohalogen compounds - A comprehensive update, Springer, Wien, 2010; (c) G. W. Gribble, Prog. Heterocycl. Chem., 2003, 15, 58.

2 (a) S. Purser, P. R. Moore, S. Swallow and V. Gouverneur, Chem. Soc. Rev., 2008, 37, 320; (b) M. Z. Hernandes, S. M. T. Cavalcanti, D. R. M. Moreira, W. F. de Azeved Jr. and A. C. L. Leite, Curr. Drug Targets, 2010, 11, 303; (c) F. Adasme-Carreno, C. MuñozGutierrez and J. H. Alzate-Morales, RSC Adv., 2016, 6, 61837; (d) S. Jiang, L. Zhang, D. Cui, Z. Yao, B. Gao, J. Lin and D. Wei, Sci. Rep., 2016, 6, 34750.

3 P. Jeschke, W. Kramer, U. Schirmer and M. Witschel, Modern Methods in Crop Protection Research, Wiley-VCH, Weinheim, 2013, ch. 4, pp. 73-119.

4 (a) M. L. Tang and Z. Bao, Chem. Mater., 2011, 23, 446; (b) F. Yang, C. Li, W. Lai, A. Zhang, H. Huang and W. Li, Mater. Chem. Front., 2017, 1, 1389-1395.

5 G. Cavallo, P. Metrengolo, R. Milani, T. Pilati, A. Priimagi, G. Resnati and G. Terraneo, Chem. Rev., 2016, 116, 2478.

6 (a) C. Hollingworth and V. Gouverneur, Chem. Commun., 2012, 48, 2929; (b) T. Umemoto, J. Fluorine Chem., 2014, 167, 3; (c) M. G. Campbell and
T. Ritter, Chem. Rev., 2015, 115, 612; (d) J.-D. Yang, Y. Wang, X.-S. Xue and J.-P. Cheng, J. Org. Chem., 2017, 82, 4129.

7 (a) I. Lengyel, V. Cesare and R. Stephani, Synth. Commun., 1998, 28, 1891; (b) X. Wan, Z. Ma, B. Li, K. Zhang, S. Cao, S. Zhang and Z. Shi, J. Am. Chem. Soc., 2006, 128, 7416; (c) N. Ahlsten, A. Bermejo Gómez and B. Martín-Matute, Angew. Chem., Int. Ed., 2013, 52, 6273; (d) R. A. Rodriguez, C.-M. Pan, Y. Yabe, Y. Kawamata, M. D. Eastgate and P. S. Baran, J. Am. Chem. Soc., 2014, 136, 6908; (e) S. M. Maddox, C. J. Nalbandian, D. E. Smith and J. L. Gustafson, Org. Lett., 2015, 17, 1042; $(f)$ M. Wang, Y. Zhang, T. Wang, C. Wang, D. Xue and J. Xiao, Org. Lett., 2016, 18, 1976.

8 (a) O. A. Attanasi, S. Beretta, G. Favi, P. Filippone, G. Mele, G. Moscatelli and R. Saladino, Org. Lett., 2006, 8, 4291; (b) F. Mo, J. M. Yan, D. Qiu, F. Li, Y. Zhang and J. Wang, Angew. Chem., Int. Ed., 2010, 49, 2028; (c) A. Bermejo Gómez, E. Erbing, M. Batuecas, A. Vázquez-Romero and B. Martín-Matute, Chem. - Eur. J., 2014, 20, 10703; (d) I. Saikia, A. J. Borah and P. Phukan, Chem. Rev., 2016, 116, 6837; (e) M. H. Shinde and U. A. Kshirsagar, Green Chem., 2016, 18, 1455.

9 (a) J. Barluenga, Pure Appl. Chem., 1999, 71, 431 and references therein; (b) J. Barluenga, J. M. González, M. A. G. Martín, P. J. Campos and G. Asensio, J. Org. Chem., 1993, 58, 2058; (c) R. Johnsson, A. Meijer and U. Ellervik, Tetrahedron, 2005, 61, 11657; (d) X.-C. Wang, Y. Hu, S. Bonacorsi, Y. Hong, R. Burrell and J.-Q. Yu, J. Am. Chem. Soc., 2013, 135, 10326; (e) J. He, J. Duan, H. Shi, J. Huang, J. Huang, L. Yu, M. Zeller, A. D. Hunter and Z. Xu, J. Inorg. Chem., 2014, 53, 6837; $(f)$ D. T. Racys, S. A. I. Sharif, S. L. Pimlott and A. Sutherland, J. Org. Chem., 2016, 81, 772; $(g)$ Y. Yang, L. Zhang, G.-J. Deng and H. Gong, Sci. Rep., 2017, 7, 40430.

10 (a) J. Barluenga, M. Marco-Arias, F. González-Bobes, A. Balleteros and J. M. González, Chem. Commun., 2004, 2616; (b) S. Stavber, M. Jereb and M. Zupan, Synthesis, 2008, 1487; (c) R. Singha, S. Dhara and J. K. Ray, RSC Adv., 2013, 3, 23989; (d) S. Song, X. Sun, X. Li, Y. Yuan and N. Jiao, Org. Lett., 2015, 17, 2886; (e) J. Iskra and S. S. Murphree, Tetrahedron Lett., 2017, 58, 645.

11 (a) N. Ahlsten and B. Martín-Matute, Chem. Commun., 2011, 47, 8331; (b) A. Bartoszewicz, M. Livendahl and B. Martín-Matute, Chem. - Eur. J., 2008, 14, 10547; (c) N. Ahlsten and B. Martín-Matute, Adv. Synth. Catal., 2009, 351, 2657.

12 Related metal-free isomerization example; S. Martinez-Erro, A. Sanz-Marco, A. Bermejo Gómez, A. Vázquez-Romero, M. S. G. Ahlquist and B. Martín-Matute, J. Am. Chem. Soc., 2016, 138, 13408.

13 E. Erbing, A. Vázquez-Romero, A. Bermejo Gómez, A. E. Platero-Prats, F. Carson, X. Zou, P. Tolstoy and B. Martín-Matute, Chem. - Eur. J., 2016, 22, 15659.

14 (a) P. C. Meltzer, D. Butler, J. R. Deschamps and B. K. Madras, J. Med. Chem., 2006, 49, 1420; (b) R. W. Evans, J. R. Zbieg, S. Wu, W. Li and D. W. C. MacMillan, J. Am. Chem. Soc., 2013, 135, 16074; (c) S. Guha, V. Rajeshkumar, S. S. Kotha and G. Sekar, Org. Lett., 2015, 17, 406; (d) S. Liang, C.-C. Zeng, H.-Y. Tian, B.-G. Sun, X.-G. Luo and F.-Z. Ren, J. Org. Chem., 2016, 81, 11565. 